\title{
Novel Modulator for the Hybrid Two-cell Flying-Capacitor Based ANPC Converter
}

\author{
Jose I. Leon*, Leopoldo G. Franquelo*, Samir Kouro ${ }^{+}$, Bin $\mathrm{Wu}^{+}$and Sergio Vazquez* \\ * Electronic Engineering Department \\ University of Seville \\ Seville, Spain 41092 \\ Email: jileon@gte.esi.us.es \\ + Department of Electrical and Computer Engineering \\ Ryerson University \\ Toronto, Canada \\ Email: skouro@ee.ryerson.ca
}

\begin{abstract}
Among the multilevel converters present in the industry, the hybrid flying-capacitor based active-neutral-pointclamped converter is very recent. It presents good features such as high quality output voltage, high modularity and easy extension to achieve a high number of levels with reduced number of power devices. This paper introduces a simple modulator for the single-phase two-cell hybrid flying-capacitor based activeneutral-point-clamped converter. The modulation technique is based on the determination of a switching sequence formed by two switching states which generate the two nearest voltage levels to the reference phase voltage. Some extra calculations are added to the modulation method to control the dc-link capacitors and the floating capacitor voltages. The computational cost of the modulation technique is low only including simple comparisons and mathematical expressions. Simulation results show the high quality output voltages and currents including the dc voltage control.
\end{abstract}

\section{INTRODUCTION}

In the last years, multilevel converters have had a great industrial impact in the high-power medium-voltage applications such as pumps, fans, large conveyors, HVDC systems, direct-drive converters for wind energy systems and ship propulsion among others. Among the advantages introduced by the multilevel converters, high quality output waveforms, high modularity and low dv/dt's have been highlighted. It can be affirmed that the multilevel converter technology has achieved a medium level of maturity and, in the last decade, a large number of commercial products can be found in the market with neutral-point-clamped (NPC), flying capacitor (FC) and cascaded H-bridge (CHB) topologies [1]-[3].

Problems and concerns about the minimization of the power losses, the balancing of the dc-link capacitors, the modulation methods complexity and the accuracy of the control strategies have been deeply studied in the last decades. Specially, the three-level NPC converter is nowadays the most deeply studied and commercialized topology all over the world achieving a nominal power up to 44 MVA [1]. One of the problems of this topology is the unequal loss distribution among the power semiconductors. This issue has been deeply studied in the last years and it has been solved introducing the three-level active-NPC (ANPC) converter where active switches are used instead the clamping diodes [4]. The ANPC topology has been implemented by $\mathrm{ABB}$ as a power electronic building block to form IGCT based high voltage converters [5]. However, the extension of the ANPC converter is not easy and a new family of hybrid ANPC converters has recently been born. This paper is focused in one of these hybrid solutions: the sevel-level flying-capacitor based ANPC converter.

\section{The Hybrid Flying-CAPACITOR BASED ANPC CONVERTER}

In last years, a hybrid flying-capacitor based ANPC topology has been introduced [6]. This converter topology is formed by the series connection of a three-level ANPC and floating capacitor power cells. As an example, the single-phase hybrid ANPC converter with one floating capacitor cell is shown in Fig. 1A. The possible switching states of this topology are introduced in Table I. Usually, this converter is named five-level hybrid ANPC (5L-ANPC) because it achieves five symmetrical output voltage levels in the phase voltage $\left(v_{a}\right)$ if the floating capacitor voltage $V_{f a}$ is equal to $V_{d c} / 2$. Recently, the 5L-ANPC topology has been proposed to be applied to wind power applications working as a $6 \mathrm{MVA}$ inverter connected to a three-level ANPC active-front-end [7]. ABB has commercialized the 5L-ANPC topology as a IGBT based back-to-back converter in the ACS2000 medium voltage drive. $\mathrm{ABB}$ introduced the converter for applications such as pumps, fans, conveyors, extruders, mixers, compressors and mills [5].

The 5L-ANPC topology can be extended to generate a higher number of levels by adding extra floating capacitor cells. The single-phase hybrid ANPC converter with two floating capacitor cells is shown in Fig. 1B. The switching states of this topology are summarized in Table II. This converter can be named seven-level hybrid ANPC (7L-ANPC) because it achieves seven symmetrical output voltage levels if the floating capacitor voltages $V_{f a 1}$ and $V_{f a 2}$ are equal to $2 V_{d c} / 3$ and $V_{d c} / 3$ respectively. This paper is focused on the introduction of a novel and simple modulation technique for a 7L-ANPC converter. 


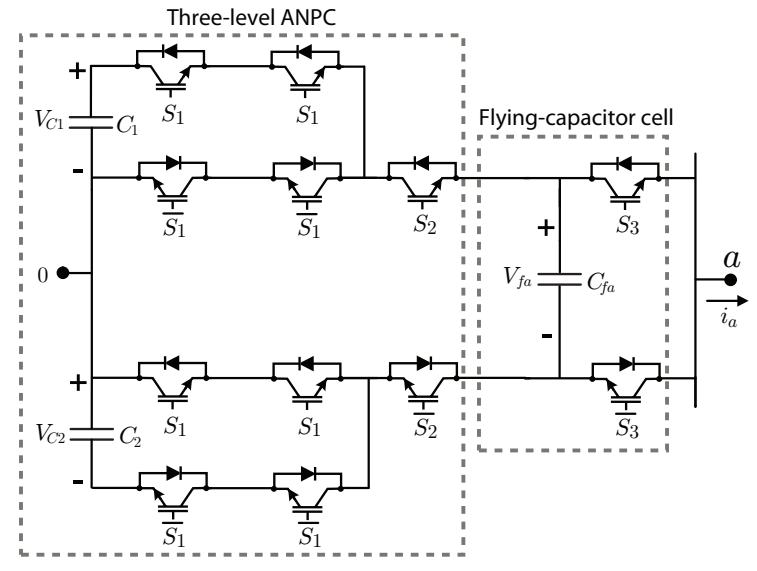

A)

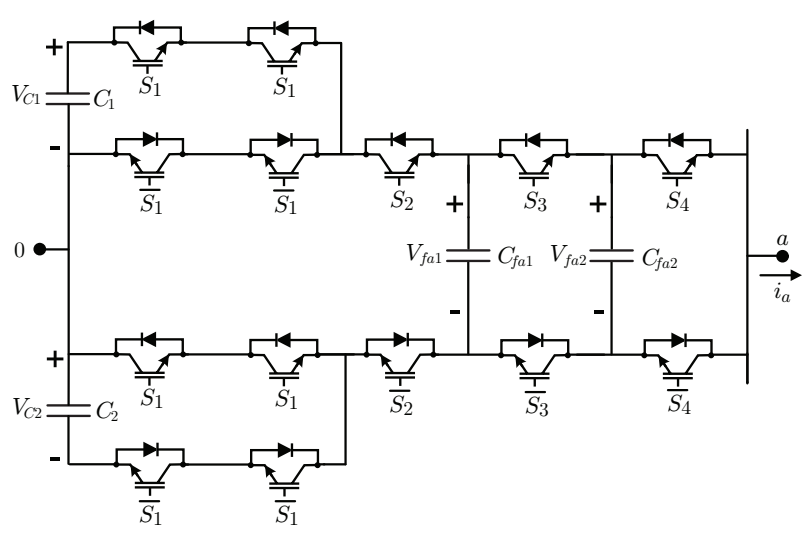

B)

Fig. 1. Hybrid ANPC topology formed by the series connection of a three-level ANPC and floating capacitor power cells. A) Five-level topology if $V_{f a}=V_{d c} / 2$. B) Seven-level topology if $V_{f a 1}=2 V_{f a 2}=2 V_{d c} / 3$.

TABLE I

One-CEll Hybrid Flying-CAPACitor BASEd ACtive-NPC SWitching States.

\begin{tabular}{cccccccc}
\hline \hline$S_{1}$ & $S_{2}$ & $S_{3}$ & Phase voltage $v_{a}$ & $\begin{array}{c}\text { Phase voltage } v_{a} \\
\text { if } V_{C 1}=V_{C 2}=2 V_{f a}=V_{d c}\end{array}$ & $\begin{array}{c}\text { Influence on } \\
V_{f a} \text { if } i_{a}>0\end{array}$ & $\begin{array}{c}\text { Influence on } \\
V_{C 1} \text { if } i_{a}>0\end{array}$ & $\begin{array}{c}\text { Influence on } \\
V_{C 2} \text { if } i_{a}>0\end{array}$ \\
\hline 0 & 0 & 0 & $-V_{C 2}$ & $-V_{d c}$ & - & - & - \\
0 & 0 & 1 & $V_{f a}-V_{C 2}$ & $-V_{d c} / 2$ & $\downarrow$ & $\uparrow$ & - \\
0 & 1 & 0 & $-V_{f a}$ & $-V_{d c} / 2$ & $\uparrow$ & $\uparrow$ & $\downarrow$ \\
0 & 1 & 1 & 0 & 0 & - & $\uparrow$ & $\downarrow$ \\
1 & 0 & 0 & 0 & 0 & $\uparrow$ & - & $\downarrow$ \\
1 & 0 & 1 & $V_{f a}$ & $V_{d c} / 2$ & - & - \\
1 & 1 & 0 & $V_{C 1}-V_{f a}$ & $V_{d c} / 2$ & $V_{d c}$ & - \\
1 & 1 & 1 & $V_{C 1}$ & & & - & - \\
\hline \hline
\end{tabular}

TABLE II

Two-CEll Hybrid Flying-CAPACITOR BASEd ACtive-NPC SWitching States.

\begin{tabular}{|c|c|c|c|c|c|c|c|c|c|}
\hline$S_{1}$ & $S_{2}$ & $S_{3}$ & $S_{4}$ & Output voltage $v_{a}$ & $\begin{array}{l}\text { Output voltage } v_{a} \\
\text { if } V_{f 1}=2 V_{f 2}=V_{d c} / 3\end{array}$ & $\begin{array}{l}\text { Influence on } \\
V_{f a 1} \text { if } i_{a}>0\end{array}$ & $\begin{array}{c}\text { Influence on } \\
V_{f a 2} \text { if } i_{a}>0\end{array}$ & $\begin{array}{l}\text { Influence on } \\
V_{C 1} \text { if } i_{a}>0\end{array}$ & $\begin{array}{l}\text { Influence on } \\
V_{C 2} \text { if } i_{a}>0\end{array}$ \\
\hline 0 & 0 & 0 & 0 & $-V_{C 2}$ & $-V_{d c}$ & - & - & - & - \\
\hline 0 & 0 & 0 & 1 & $V_{f a 2}-V_{C 2}$ & $-2 V_{d c} / 3$ & - & $\downarrow$ & - & - \\
\hline 0 & 0 & 1 & 0 & $-V_{f a 2}+V_{f a 1}-V_{C 2}$ & $-2 V_{d c} / 3$ & $\downarrow$ & $\uparrow$ & - & - \\
\hline 0 & 1 & 0 & 0 & $-V_{f a 1}$ & $-2 V_{d c} / 3$ & $\uparrow$ & - & $\uparrow$ & $\downarrow$ \\
\hline 0 & 0 & 1 & 1 & $V_{f a 1}-V_{C 2}$ & $-V_{d c} / 3$ & $\downarrow$ & - & - & - \\
\hline 0 & 1 & 0 & 1 & $V_{f a 2}-V_{f a 1}$ & $-V_{d c} / 3$ & $\uparrow$ & $\downarrow$ & $\uparrow$ & $\downarrow$ \\
\hline 0 & 1 & 1 & 0 & $-V_{f a 2}$ & $-V_{d c} / 3$ & - & $\uparrow$ & $\uparrow$ & $\downarrow$ \\
\hline 0 & 1 & 1 & 1 & 0 & 0 & - & - & $\uparrow$ & $\downarrow$ \\
\hline 1 & 0 & 0 & 0 & 0 & 0 & - & - & $\uparrow$ & $\downarrow$ \\
\hline 1 & 0 & 0 & 1 & $V_{f a 2}$ & $V_{d c} / 3$ & - & $\downarrow$ & $\uparrow$ & $\downarrow$ \\
\hline 1 & 0 & 1 & 0 & $-V_{f a 2}+V_{f a 1}$ & $V_{d c} / 3$ & $\downarrow$ & $\uparrow$ & $\uparrow$ & $\downarrow$ \\
\hline 1 & 1 & 0 & 0 & $-V_{f a 1}+V_{C 1}$ & $V_{d c} / 3$ & $\uparrow$ & - & - & - \\
\hline 1 & 0 & 1 & 1 & $V_{f a 1}$ & $2 V_{d c} / 3$ & $\downarrow$ & - & $\uparrow$ & $\downarrow$ \\
\hline 1 & 1 & 0 & 1 & $V_{f a 2}-V_{f a 1}+V_{C 1}$ & $2 V_{d c} / 3$ & $\uparrow$ & $\downarrow$ & - & - \\
\hline 1 & 1 & 1 & 0 & $-V_{f a 2}+V_{C 1}$ & $2 V_{d c} / 3$ & - & $\uparrow$ & - & - \\
\hline 1 & 1 & 1 & 1 & $V_{C 1}$ & $V_{d c}$ & - & - & - & - \\
\hline
\end{tabular}

In general, for a N-level hybrid ANPC converter, $k$ floating capacitor cells $(\mathrm{N}=2 k+3)$ are needed and their desired voltage values $V_{f a i}^{*}(i=1, \ldots, k)$ are equal to $(k+1-i) V_{d c} /(k+1)$. This information is summarized in Table III.

\section{Proposed Modulator FOR THE Single-Phase 7L-ANPC CONVERTER}

As can be observed in Table I and Table II, there are several switching states which obtain the same output voltage and affect to the flying capacitor voltages in opposite way. Previous publications have shown the good performance of 
TABLE III

DESIRED VOLTAGES OF THE FLYING CAPACITORS OF THE HYBRID ANPC TOPOLOGY DEPENDING ON THE NUMBER OF FLOATING CAPACITOR CELLS

\begin{tabular}{|c|c|c|c|c|c|c|}
\hline $\begin{array}{l}\text { Number of levels } \\
\mathrm{N}\end{array}$ & $\begin{array}{l}\text { Number of floating capacitor cells } \\
\qquad \mathrm{k}\end{array}$ & $V_{f a 1}^{*}$ & $V_{f a 2}^{*}$ & $V_{f a 3}^{*}$ & $\ldots$ & $V_{f a k}^{*}$ \\
\hline 5 & 1 & $V_{d c} / 2$ & - & - & $\ldots$ & - \\
\hline 7 & 2 & $2 V_{d c} / 3$ & $V_{d c} / 3$ & - & $\ldots$ & - \\
\hline 9 & 3 & $3 V_{d c} / 4$ & $2 V_{d c} / 4$ & $V_{d c} / 4$ & $\ldots$ & - \\
\hline$\ldots$ & $\ldots$ & $\ldots$ & $\ldots$ & $\ldots$ & $\ldots$ & \\
\hline $\mathrm{N}$ & $(\mathrm{N}-1) / 2$ & $k V_{d c} /(k+1)$ & $(k-1) V_{d c} /(k+1)$ & $(k-2) V_{d c} /(k+1)$ & $\ldots$ & $V_{d c} /(k+1)$ \\
\hline
\end{tabular}

the dc voltage control of the flying capacitor of the $5 \mathrm{~L}$ ANPC by choosing properly the redundant switching states of the switching sequence. Recently a space-vector modulation technique has been applied to a three-phase 5L-ANPC for the rectifier side of a back-to-back configuration [8]. The control region of the converter is the well-known hexagon plotted in the alpha-beta frame where the switching states are located. The switching sequence and the duty cycles are determined using the three nearest switching states to the reference vector. However, it has to be noticed that, the level of flexibility and complexity is really significant because of the high number of different output voltage vectors. This fact becomes critical when a higher number of levels is considered in the hybrid flying-capacitor based ANPC converter.

Pre-programmed modulation techniques such as the selective harmonic elimination (SHE) have been also addressed for this converter topology. In these methods, the switching of the converter is determined offline to eliminate the harmonic distortion of some low order harmonics. A similar preprogrammed modulation technique has been also introduced to minimize online the overall total harmonic distortion. The voltage level to be generated by the converter is obtained online taking into account the best possible switching to achieve the floating voltage control [9]-[12].

Finally, several multi-carrier based pulse width-modulation (PWM) technique have been introduced to be applied to the hybrid flying-capacitor based ANPC converter. The multicarrier PWM techniques are level-shifted [7] or phase-shifted techniques [13]. The phase-shifted solution represents a good solution because it achieves a natural balance of the flying capacitors of the converter. However, its dynamic performance is poor when a large load step is applied to the converter.

In this paper, a simple modulation technique for the $7 \mathrm{~L}$ ANPC is proposed. This method is based on the generation of the reference phase voltage as an average of the nearest voltage levels. In this way, the modulation problem is reduced to very simple calculations determining easily the switching sequence (formed by two switching states for each phase of the converter) and the corresponding switching times. The proposed modulator includes as an additional control target the balance the flying-capacitors of the hybrid ANPC converter. The balancing control algorithm is based on choosing the proper redundant switching state taking into account the instantaneous values of the direction of the phase current and the flying capacitor imbalances.
In the proposed modulator, the following mathematical definitions are necessary:

$$
\begin{aligned}
a & =3 \frac{V_{r e f}+V_{d c}}{V_{d c}} \\
a_{i} & =f l o o r(a) \\
\operatorname{error}_{a} & =\left[\begin{array}{c}
V_{f a 1}-V_{f a 1}^{*} \\
V_{f a 2}-V_{f a 2}^{*}
\end{array}\right]
\end{aligned}
$$

In each row of matrices $\mathbf{C}_{1}$ and $\mathbf{C}_{2}$ some possible gate signal values of variables $S_{2}, S_{3}$ and $S_{4}$ are defined. First column is focused on variable $S_{2}$. Matrix $\mathbf{C}_{1}$ includes the possible switching states where only one of the gate signals is equal to 1 . On the other hand, $\mathbf{C}_{2}$ includes the possible switching states where two gate signals are equal to 1 .

$$
\begin{aligned}
& \mathbf{C}_{1}=\left[\begin{array}{lll}
0 & 0 & 1 \\
0 & 1 & 0 \\
1 & 0 & 0
\end{array}\right] \\
& \mathbf{C}_{2}=\left[\begin{array}{lll}
0 & 1 & 1 \\
1 & 0 & 1 \\
1 & 1 & 0
\end{array}\right]
\end{aligned}
$$

On the other hand, matrices $\mathbf{M}_{1}$ and $\mathbf{M}_{2}$ define the influence of the switching states defined by matrices $\mathbf{C}_{1}$ and $\mathbf{C}_{2}$ respectively on the floating capacitor voltages $V_{f a 1}$ and $V_{f a 2}$. First and second columns are focused on variables $V_{f a 1}$ and $V_{f a 2}$ respectively. When the phase current $i_{a}$ is negative and an specific switching state is applied to the 7L-ANPC, if the floating capacitor voltage increases, the associated element in matrix $\mathbf{M}_{1}$ or $\mathbf{M}_{2}$ is equal to 1 . If floating capacitor voltage remains constant is equal to 0 and finally the element is equal to -1 if the floating capacitor voltage decreases.

$$
\begin{aligned}
& \mathbf{M}_{1}=\left[\begin{array}{rr}
0 & 1 \\
1 & -1 \\
-1 & 0
\end{array}\right] \\
& \mathbf{M}_{2}=\left[\begin{array}{rr}
1 & 0 \\
-1 & 1 \\
0 & -1
\end{array}\right]
\end{aligned}
$$

The flow diagram of the single-phase modulator for the 7L-ANPC converter is shown in Fig. 2. In the flow diagram represented in Fig. 2, the switching variable $S_{i}(i=1,2,3,4)$ 

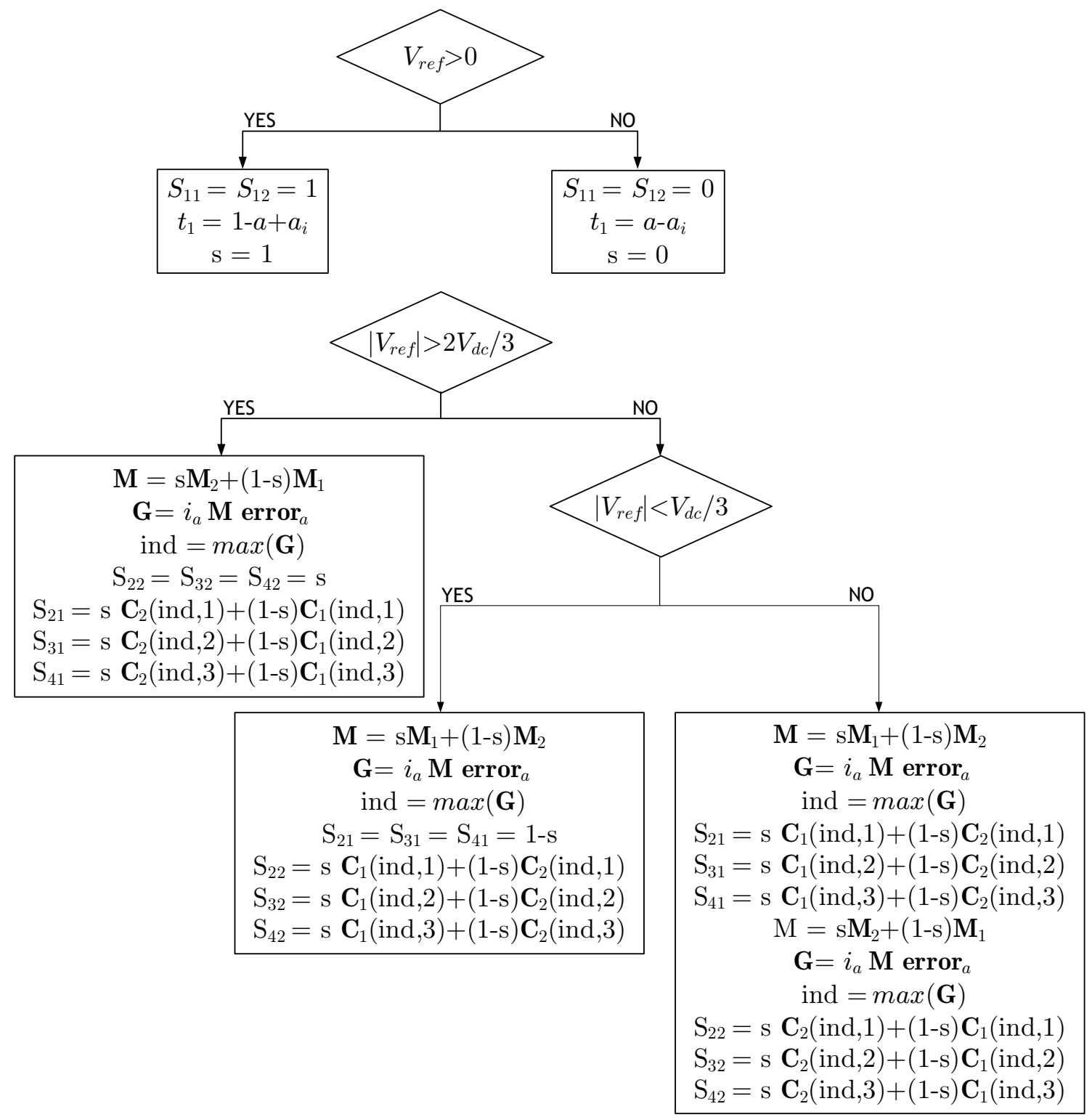

Fig. 2. Flow diagram of the single-phase modulator for the 7L-ANPC converter with flying capacitor voltages control.

takes the value $S_{i 1}$ during $t_{1} / 2, S_{i 2}$ during $1-t_{1}$ and finally again $S_{i 1}$ during $t_{1} / 2$. Using the proposed modulator, a maximum of only one switching is present during the sampling time $T_{s}$ in each power semiconductor couple commanded by variables $S_{1}, S_{2}, S_{3}$ and $S_{4}$. The switching signal $S_{1}$ is simply generated by comparing the reference voltage $V_{\text {ref }}$ with zero. Therefore, the modulator forces a fundamental switching frequency in the power semiconductors commanded by $S_{1}$ leading to a reduction of the switching losses of the system. This reduction is due to the fact that $S_{1}$ commands the switching state of eight power semiconductors while $S_{2}$, $S_{3}$ and $S_{4}$ command the state of a couple them respectively. Operator floor $(x)$ rounds the elements of $x$ to the nearest integers towards minus infinity. Operator $\max (x)$ returns the index of the maximum values in vector $x$. If this value is repeated in the vector, the index of the first one is returned.

All the possible redundant switching states are considered in the flow diagram of the single-phase modulator for the 7LANPC converter shown in Fig. 2. The computational cost of the modulation technique is low only including simple comparisons and mathematical expressions. When several redundant switching states can be applied, the actual operation point of the 7L-ANPC is considered in order to determine the final switching state to be part of the switching sequence. In the flow diagram, vector $g$ determines the positive or negative influence of each possible switching state taking into account the matrix $\mathbf{M}_{1}$ or $\mathbf{M}_{2}$, the actual value of the phase current $i_{a}$ and the dc voltage imbalances in the flying capacitors. In this way, the element of vector $G$ with maximum value, called ind in the flow diagram, determine the final switching state from the corresponding row of matrix $\mathbf{C}_{1}$ or $\mathbf{C}_{2}$. In fact, this 
method implies a minimization of the electrical energy stored in the dc-link capacitors [14], [15]. The minimization of this parameter directly means the minimization of the averaged imbalance in the dc-link voltage.

\section{RESUlts OF THE MOdUlator FOR THE Single-Phase 7L-ANPC CONVERTER}

The proposed modulator has been applied to the 7L-ANPC topology where the dc-link capacitors $C_{1}$ and $C_{2}$ are equal to $3 \mathrm{mF}$, the floating capacitors $C_{f a 1}$ and $C_{f a 2}$ are equal to $2 \mathrm{mF}$ and the total voltage of the dc-link $2 V_{d c}$ is equal to 3000 volts. The total dc-link voltage is kept constant by an active front end. The desired floating capacitor voltages $V_{f a 1}$ and $V_{f a 2}$ are equal to 1000 volts and 500 volts respectively. The 7L-ANPC is connected to a resistive-inductive load formed by the series connection of $\mathrm{R}=10 \Omega$ and $\mathrm{L}=3 \mathrm{mH}$. The reference voltage $V_{\text {ref }}$ is a pure sinusoidal voltage with an amplitude equal to 1500 volts. The floating capacitor is initially discharged starting from zero volts. The sampling frequency $f_{s}$ of the modulator is equal to $800 \mathrm{~Hz}$.

The flow diagram introduced in Fig. 2 is applied to the single-phase 7L-ANPC converter and the obtained results are represented in Fig. 3 where the phase voltage $v_{a}$, the phase current $i_{a}$, the flying capacitor voltages $V_{f a 1}$ and $V_{f a 2}$ and a half of the dc-link voltage $V_{C 1}$ are represented. A detail of the phase voltage and current, the floating capacitor voltages and a half of the dc-link voltage in steady state conditions is shown in Fig. 4. It can be observed that the floating capacitor voltages achieve their desired values while the phase voltage and current have high quality. The switching frequency of power semiconductors commanded by $S_{1}$ is $50 \mathrm{~Hz}$ while the average switching frequency of $S_{2}, S_{3}$ and $S_{4}$ is around $500 \mathrm{~Hz}$.

As can be observed in Fig. 3 and Fig. 4, the dc-link capacitors voltages are naturally balanced because the voltage of capacitor $C_{1}\left(V_{C 1}\right)$ remains around 1500 volts (the half of the total dc-link voltage). This phenomenon can be explained considering the experiment shown in Fig. 5 and Fig. 6. In this new test, the power converter starts the operation with an unbalanced situation in the dc-link ( $V_{C 1}$ and $V_{C 2}$ are equal to 1000 and 2000 volts respectively). The floating voltages $V_{f a 1}$ and $V_{f a 2}$ are 1000 volts and 500 volts respectively which are their desired voltages. From Fig. 5, it can be observed that the dc-link imbalance decreases achieving the desired operation point where both dc-link capacitor voltages are equal to 1500 volts. A detail of the waveforms of this experiment is shown in Fig. 6. The dc-link capacitors voltages are naturally balanced because the actual dc-link voltage imbalance creates an offset in the phase voltage. This fact leads to an offset in the phase current which directly affects to the dc-link capacitor voltages as was introduced in Table II. In this way, if the dc-link voltage $V_{C 1}$ is less than 1500 volts, a positive offset appears in the phase voltage and the phase current. This tends to increase the voltage of capacitor $C_{1}$ reducing the dc-link voltage imbalance.
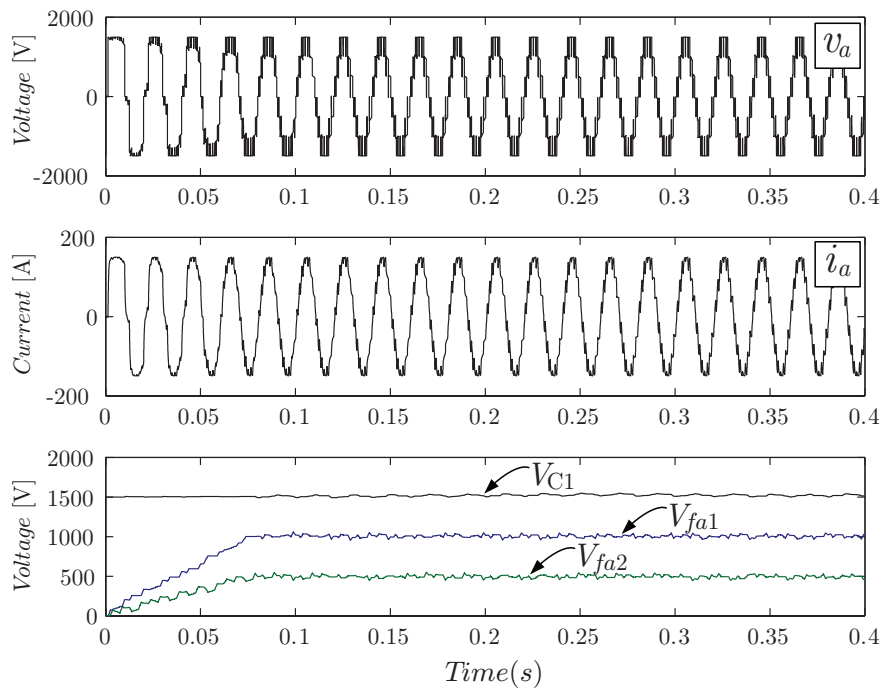

Fig. 3. Results of the proposed modulation technique applied to the singlephase 7L-ANPC. From top to bottom: Phase voltage, phase current, floating capacitor voltages and half of the dc-link voltage.
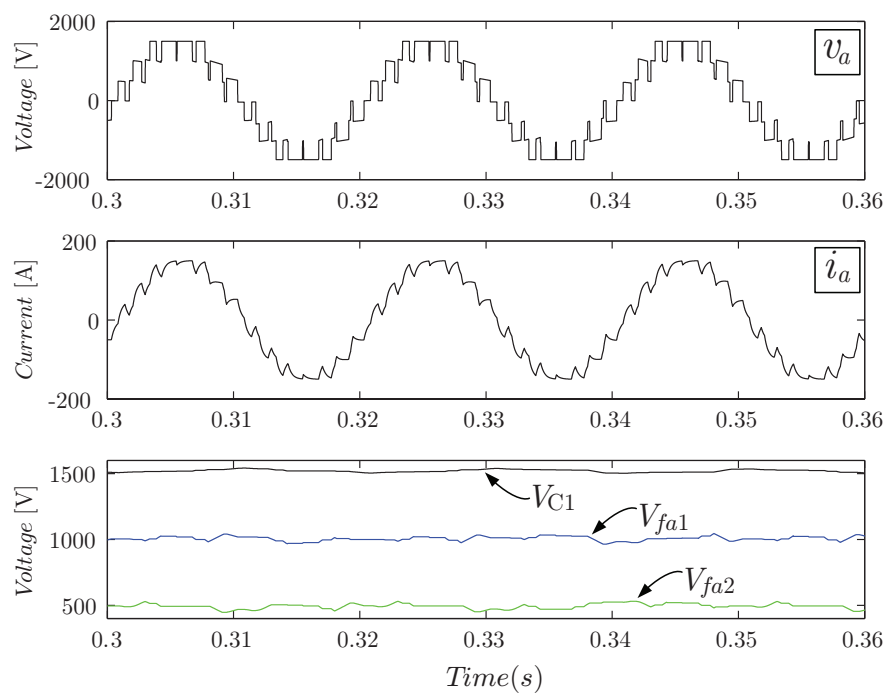

Fig. 4. Detailed results of the proposed modulation technique applied to the single-phase 7L-ANPC. From top to bottom: Phase voltage, phase current, floating capacitor voltages and half of the dc-link voltage.

\section{CONCLUSIONS}

In this paper, a seven-level hybrid flying-capacitor based ANPC topology formed by the series connection of a threelevel ANPC with two floating capacitor cells, called 7LANPC, has been studied. This paper introduces a simple modulation technique to obtain high performance output waveforms with voltage balance control of the flying capacitors and the dc-link capacitors. The proposed modulation method is based on the generation of the reference phase voltage using the two nearest voltage levels of the converter topology. As several switching states are redundant, a mathematical comparison using matrices is carried out to determine the proper switching state to achieve the dc voltage control. The 

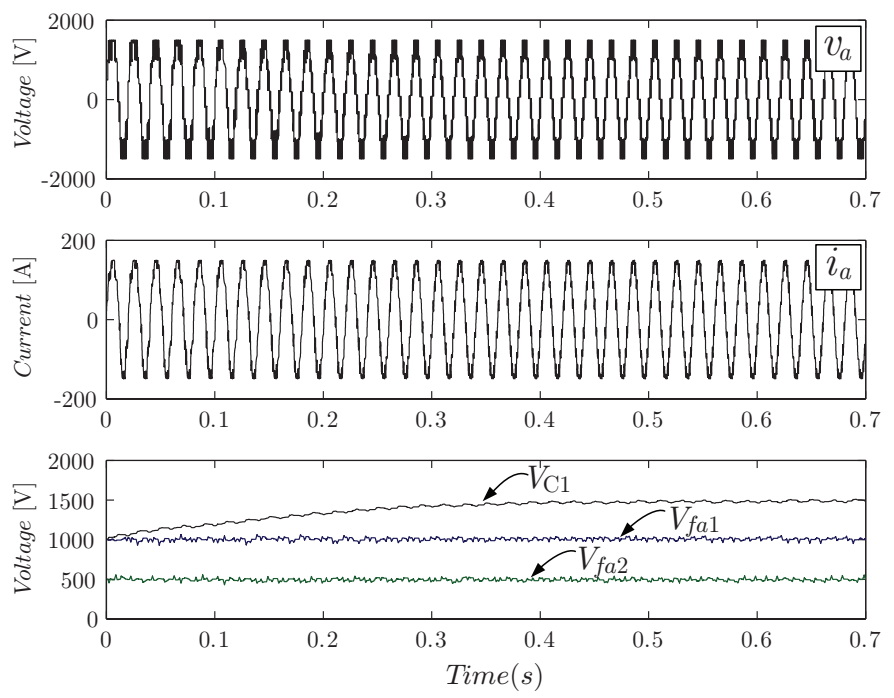

Fig. 5. Results of the proposed modulation technique applied to the singlephase 7L-ANPC starting from an unbalanced situation in the dc-link. From top to bottom: Phase voltage, phase current, half of the dc-link voltage $V_{C 1}$ and floating capacitor voltages.
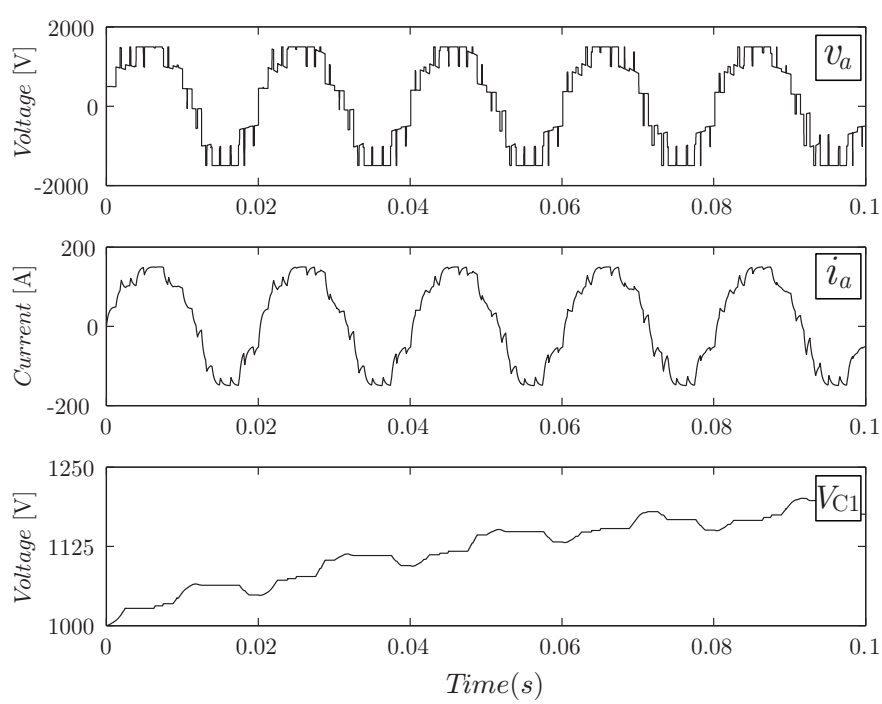

Fig. 6. Detailed Results of the proposed modulation technique applied to the single-phase 7L-ANPC starting from an unbalanced situation in the dclink. From top to bottom: Phase voltage, phase current and half of the dc-link voltage $V_{C 1}$.

proposed modulation technique takes into account the actual values of the floating capacitor voltages and the phase current. The resulting modulation technique has low computational cost only including simple equations and comparisons.

Applying the proposed modulation strategy to the singlephase 7L-ANPC, the phase capacitor voltages are controlled to their desired values. In addition, the dc-link capacitors voltages are naturally balanced due to the dc offset effect created by the modulator. The proposed modulation method can be applied with very low switching frequency. In the presented experiments, the sampling frequency of the modulator is $800 \mathrm{~Hz}$ leading to a switching frequency of the power de- vices (except $S_{1}$ which has fundamental switching frequency) around $500 \mathrm{~Hz}$. The results show the good performance of the proposed modulation method.

\section{ACKNOWLEDGMENT}

The authors gratefully acknowledge the financial support provided by the Ministry of Education under grant PR20100162 and the CCTVal $\left(\mathrm{N}^{\circ} \mathrm{FB} 0821\right)$.

\section{REFERENCES}

[1] S. Kouro, M. Malinowski, K. Gopakumar, J. Pou, L.G. Franquelo, B. Wu, J. Rodriguez, M. A. Perez and J. I. Leon, "Recent Advances and Industrial Applications of Multilevel Converters," IEEE Trans. Ind. Electron., vol. 57, no. 8, pp. 2553-2580, Aug. 2010.

[2] J. Rodriguez, L. G. Franquelo, S. Kouro, J. I. Leon, R. Portillo, M. M. Prats and M. A. Perez, "Multilevel Converters: An Enabling Technology for High-Power Applications," Proceedings of the IEEE, vol. 97, no. 11, pp. 1786-1817, Nov. 2009.

[3] L. G. Franquelo, J. Rodriguez, J. I. Leon, S. Kouro, R. Portillo and M. M. Prats, "The age of multilevel converters arrives," IEEE Ind. Electron. Magazine, vol. 2, no. 2, pp. 28-39, Jun. 2008.

[4] T. Bruckner, S. Bernet, and H. Guldner, "The active NPC converter and its loss-balancing control," IEEE Trans. Ind. Electron., vol. 52, no. 3, pp. 855-868, June 2005.

[5] ABB, "New inverter modules for optimum performance," [Online]. Available: http:// www.abb.com.

[6] P. Barbosa, P. Steimer, J. Steinke, M. Winkelnkemper and N. Celanovic, "Active-neutral-point-clamped (ANPC) multilevel converter technology," in European Conference on Power Electronics and Applications (EPE'05), pp. 1-10, 11-14 Sept. 2005, Dresden (Germany).

[7] M. Winkelnkemper, F. Wildner and P. K. Steimer, "6 MVA five-level hybrid converter for windpower," in $39^{\text {th }}$ IEEE Power Electronics Specialists Conference (PESC'08), pp. 4532-4538, 15-19 June 2008, Rhodes (Greece).

[8] F. Kieferndorf, M. Basler, L. A. Serpa, J.-H. Fabian, A. Coccia, and G. A. Scheuer, "A new medium voltage drive system based on ANPC-5L technology," in IEEE International Conference on Industrial Technology (ICIT 2010), pp. 643-649, March 2010, Valparaiso (Chile).

[9] S. R. Pulikanti and V. G. Agelidis, "Five-level active NPC converter topology: SHE-PWM control and operation principles," in Australasian Universities Power Engineering Conference (AUPEC), pp.1-5, 9-12 Dec. 2007, Perth (Australia).

[10] S. R. Pulikanti and V. G. Agelidis, "Control of neutral point and flying capacitor voltages in five-level SHE-PWM controlled ANPC converter," in 4th IEEE Conference on Industrial Electronics and Applications (ICIEA), pp. 172-177, 25-27 May 2009, Xi'an (China).

[11] J. Meili, S. Ponnaluri, L. Serpa, P. K. Steimer and J. W. Kolar, "Optimized Pulse Patterns for the 5-Level ANPC Converter for High Speed High Power Applications," in IEEE 32nd Annual Conference on Industrial Electronics (IECON), pp. 2587-2592, 6-10 Nov. 2006, Paris (France).

[12] Jun Li, Yu Liu, S. Bhattacharya and A. Q. Huang, "An optimum PWM Strategy for 5-level active NPC (ANPC) converter based on real-time solution for THD minimization," in IEEE Energy Conversion Congress and Exposition (ECCE), pp. 1976-1982, 20-24 Sept. 2009, San Jose (EEUU).

[13] S. R. Pulikanti, S. G. Konstantinou and V. G. Agelidis, "An n-level flying capacitor based active neutral-point-clamped converter," in 2nd IEEE International Symposium on Power Electronics for Distributed Generation Systems (PEDG), pp. 553-558, 16-18 June 2010, Hefei (China).

[14] M. Marchesoni, M. Mazzucchelli, F. V. P. Robinson and P. Tenca, "A minimum-energy-based capacitor voltage balancing control strategy for MPC conversion systems," in IEEE International Symposium on Industrial Electronics (ISIE), vol. 1, pp. 20-25, 12-16 July 1999, Bled (Slovenia).

[15] J. Pou, R. Pindado, D. Boroyevich, P. Rodriguez and J. Vicente, "Voltage-balancing strategies for diode-clamped multilevel converters," in IEEE 35th Annual Power Electronics Specialists Conference (PESC), vol. 5, pp. 3988-3993, 20-25 June 2004, Aachen (Germany). 